\title{
Correlations between orthodontic treatment and posture
}

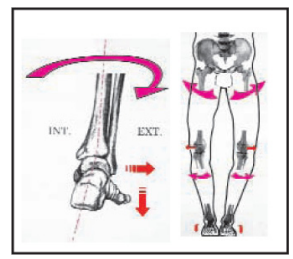

\author{
Isabelle GAULT
}

\section{ABSTRACT}

The tonic postural system controls the equilibrium of posture when the body is completely at rest and when it is moving. It is a complicated mechanism that can call into action a variety of modalities including the assistance of the feet, the skin, the eyes, the masticatory system, the Central Nervous System and the efferent muscles, with all elements working reciprocally. Orthodontists should make a postural assessment before undertaking any treatment. If problems are found they should be dealt with by a multi-disciplinary team. But in every case orthodontists should be aware that their efforts have an effect on posture and can modify the corporal schema of the patient. Orthodontists should pay special attention to patients with scoliosis or any deformity of the spinal column.

\section{KEYWORDS}

Posture

Tonic postural system

Postural treatment

Multi-disciplinary treatment

Correlation

Occlusion-posture

Corporal schema

Orthodontic treatment. 


\section{1 - INTRODUCTION}

Because dental occlusion and general posture are intimately related, it is always important for orthodontists to assess each patient's over-all posture and see how any individual malocclusion is incorporated into a possible lack of equilibrium. As our specialty matures, it is advancing from a narrow focus on the oral cavity to an assessment of the patient as a complete individual and a postural evaluation is a good example of this new approach. It makes little sense to treat a malocclu-

\section{2 - DEFINITIONS}

\section{2- 1 - Posture}

Posture is a position of the body, an attitude that has evovled over the course of phylogenetic evolution.

\section{2 - 2 - Posturology}

This is the study of the postural system and its functioning.

\section{2 - 3 - The tonic postural system}

This regulates the equillibrium of the body in space in pure static rest and in movement. It works against gravity and is continually in action when the individual is awake and is directed by the extra pyramidal system so it is, accordingly, involuntary.

The peripheral and central receptors constitute the entry pathway to the tonic postural system. They receive information about the environment and transmit it to the central nervous sion in with an associated postural deformity without also correcting that postural defect. Recent techniques have encouraged us to place "life-time" retainers in order to preserve an artificial equilibrium. The relapses that often result can be interpreted as a return to an previous stance that was an expression of the patient's original postural schema. Postural troubles can, in this way, be at the root of unhappy outcomes in orthodontic therapy.

system which sends back instructions that preserve the equilibrium of the tonic and tonico-phasic statural muscles. This loop constitutes the individual's corporal schema working as a self-maintained cybernetic regulatory system (fig. 1).

\section{2 - 3 - 1 - The receptors}

These are the elements that receive information from the surround, the exterior receptors, or the body itself,

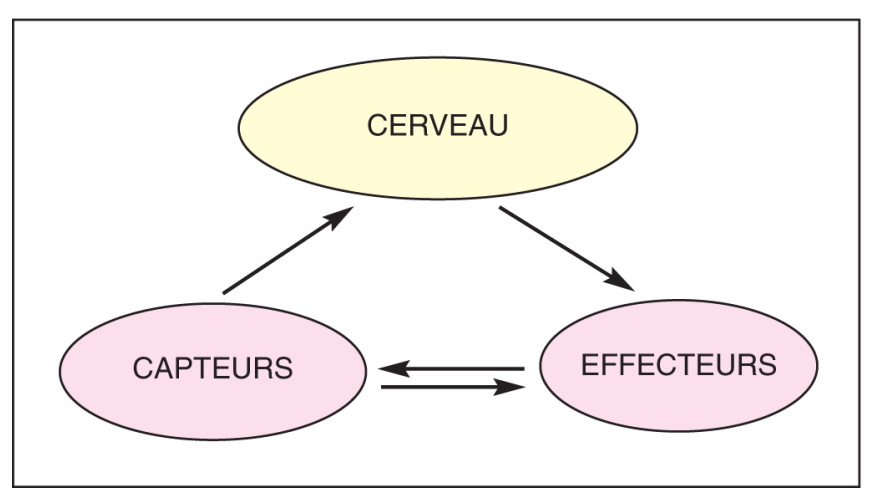

Figure 1

Schema the basis of the tonic postural system. 


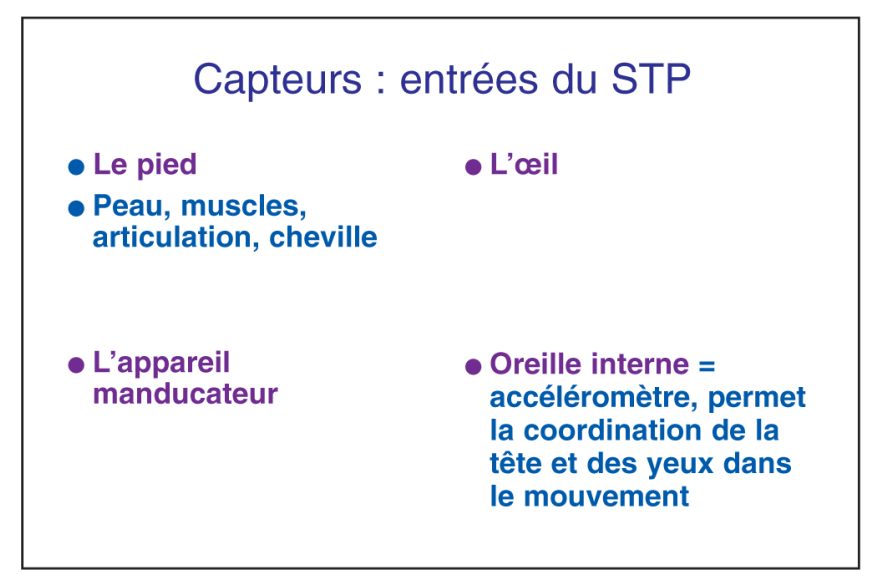

Figure 2

Receptor: Entryway to the topical postural system.

the proprioreceptors. The two principal receptor sites are the feet and the eyes. The masticatory system can interfere with posture as can the entire visceral system. Neither, strictly speaking, can be regarded as postural receptors. The inner ear is an angular and linear accelerometer that is activated during bodily movement.

A receptor can be a cause of postural difficulties when, because of some pathological change, it transmits aberrant information to the higher nervous system. It is acting in an adaptive way when its deformation results from a malfunction of another receptor or from a postural problem. This adaptation is a reversal of normal status in the beginning but it becomes fixed after 10 months. Most of the time involved receptors are both causative and adap- tive because they work reciprocally. The regulatory mechanism intervenes with short and long reflex arcs that regulate the myotatic reflex.

\section{2- 3 - 2 - At the level of the cerebrum}

This information is assessed at the level of what Dr Bricot ${ }^{2}$ has referred to $s$ the central computer, which activates the vestibular nuclei, the basal ganglions with the central grey nuclei and corpus striatum, the cerebellum, the reticular system with the mesencephalic and red nuclei, and the colliculus. The associated and commissural formations have an important role to play in communications between the right and left halves of the cerebrum.

\section{2 - 3 - 3 - The effectors}

The postural muscle chains that are aligned in continuous directions and planes to propagate the organizing forces of the body constitute the effectors. These chains are arranged in relays between the scapular and the pelvic belts. When they are stimulated asymmetrically they provoke tilting or rotations of these protective belts as well as of the spinal column. These postural muscles depend on other synergic and antagonistic muscles.

\section{3 - PRINCIPAL DEFORMATION OF THE FEET AND THEIR REPERCUSSION ON POSTURE}

The feet, which are the is principal tonic postural system receptors, are the link between disequilibrium and the ground. They can be the cause of it or reacting in adaptation, that is, they might become deformed in order to 


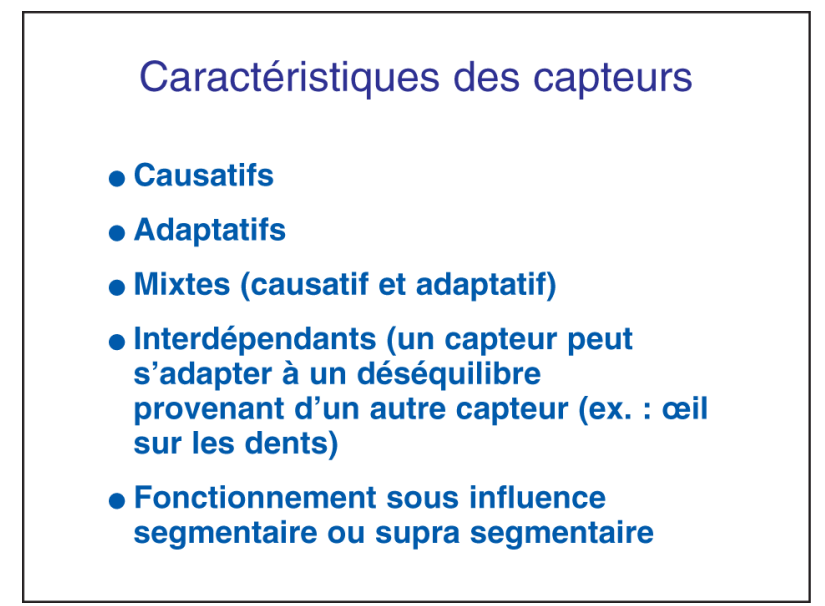

Figure 3

Characterstics of receptors.

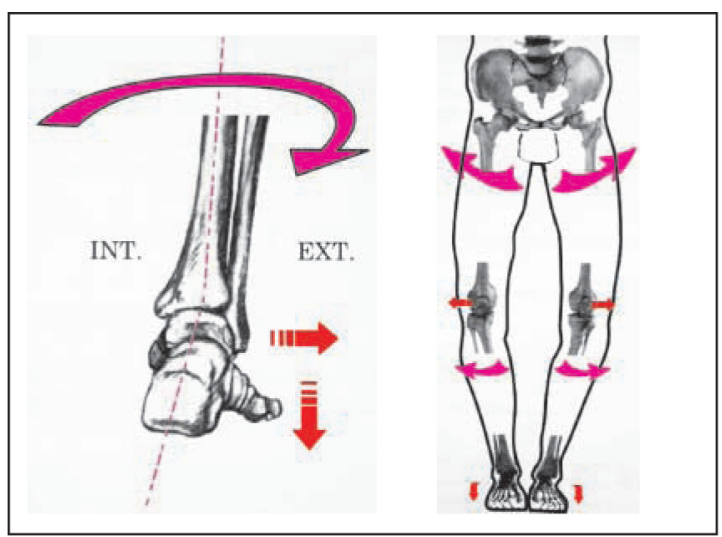

Figure 4

Hollow pigeon toe after Bricot.

maintain a maximum of contact with the ground, after pelvic tilting, for example, one foot may respond one way and the other foot not at all or differently. They could then be described as mixed feet.

\section{3 - 1 - Club foot}

A club foot is one that tilts badly to the exterior and forward, associated

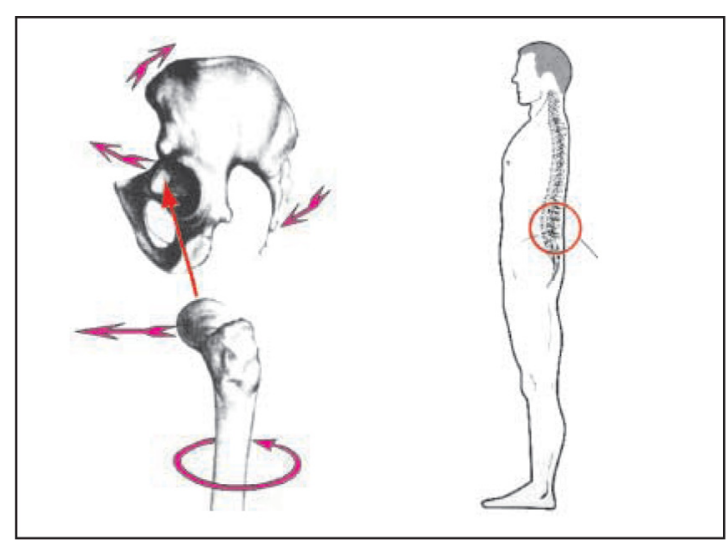

Figure 5

Pigeon toe: postural consequences, after Bricot ${ }^{2}$.

with an external tibial rotation, a tendency to a genou varum with added external pressure on the patellar clonus.

The couple of torsion on the head of the femur and the acetabelum provokes an extension of the ilium and a flexion of the sacrum causing a decrease in the lumbar curve and the flatness of the back. This postural defect is often seen with patients whose mandible is prominent.

\section{3 - 2 - The pes adductus}

The pes adductus is on the other hand one that one that caves in internally, astrago-calcanean, with an internal rotation of the tibial and femoral axes, a tendency to genou valgum with a more internal position of the patellar clonus.

The couple of twisting of the head of the femoral acetabulum causes a forward flexion of the ilium and an extension of the sacrum with a resultant increase in lumbar lordosis and dorsal cyphosis, or humpback. 


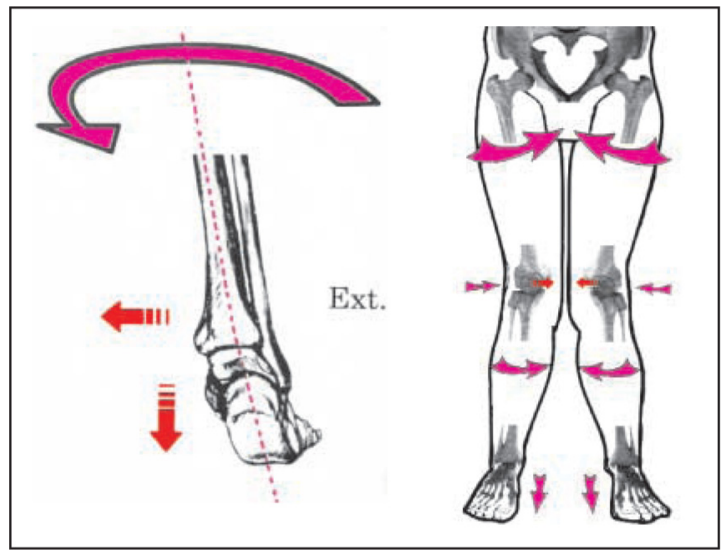

Figure 6

Valgus flat foot after Bricot ${ }^{2}$.

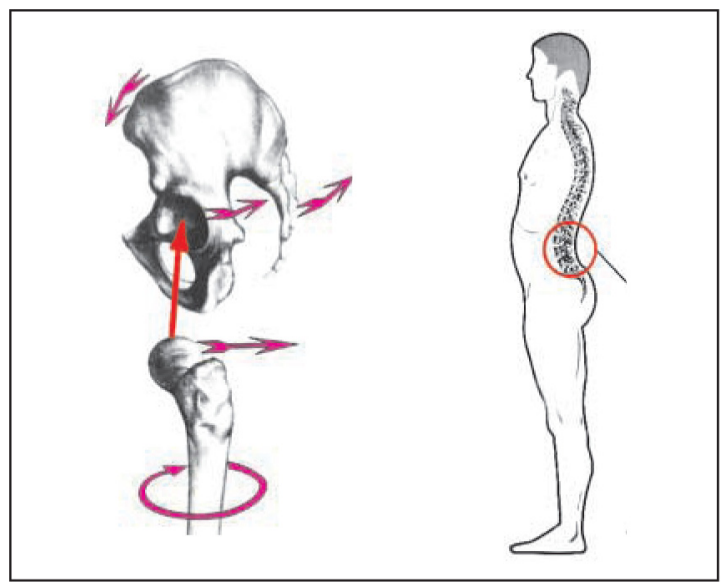

Figure 7

Flat foot resulting from postural imbalance after Bricot ${ }^{2}$.

\section{3 - 3 - Asymmetrical feet}

Feet are rarely deformed symmetrically. One foot will deviate more than its mate, or there may be varus on one side and valgus on the other. So feet not in harmony contribute to the postural disequilibrium. A pelvic tilt can exist when legs are of the same length.
If the scapular and the pelvic muscular belts don't play their roles properly scoliosis or a tendency to scoliosis may appear. But if they do exert their buffering action, the spinal column remains upright. Toubol and Perez have demonstrated the adaptative effect of the masticatory system experimentally. A slight change in the way the feet bear on the ground 


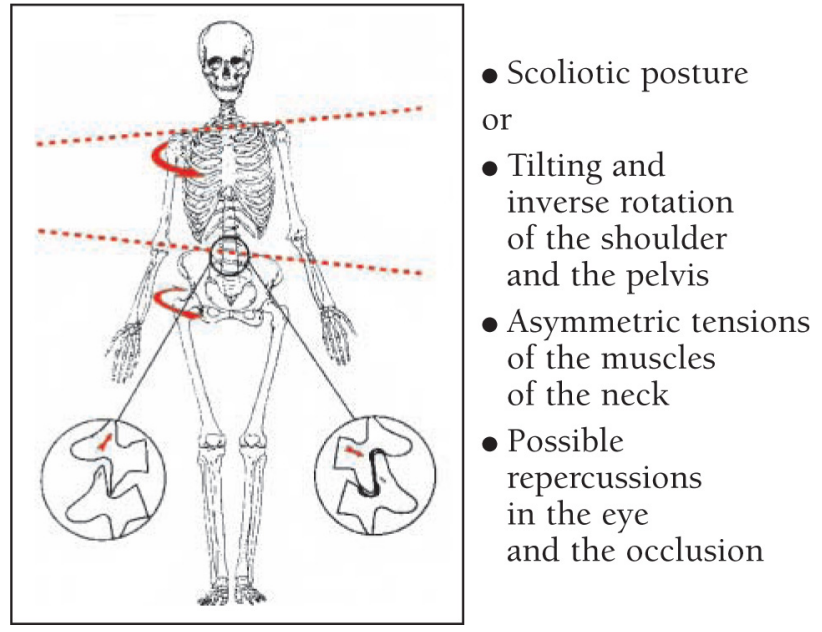

Figure 8

Asymmetrical feet after Bricot ${ }^{2}$.

modifies mastication. Patients' seated axiographic registrations differ from those made when they are standing.

\section{3 - 4 - The ocular receptor}

The eye is the second receptor of the tonic postural system. It introduces perception of the exterior through refraction (where problems are often detected and treated in children.) and proprioception of the extra-ocular muscles. The principle ocular muscular problem is insufficient convergence and heterophoria, difficulty with parallelism of the visual axes. Hypoconvergence usually affects the dominant, or non-directing eye. Defects of convergence and heterophorias cause a new integration of the corporal schema, disequilibrium of posture with homolateral tilting of the shoulder and the pelvis.

Examiners can easily test ocular convergence after having stimulated

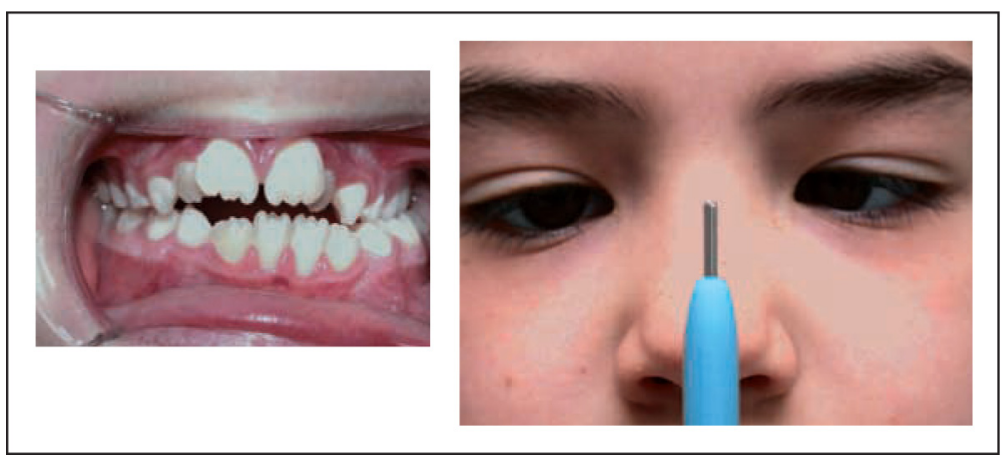

Figure 9

Cross bites and convergence problems. 


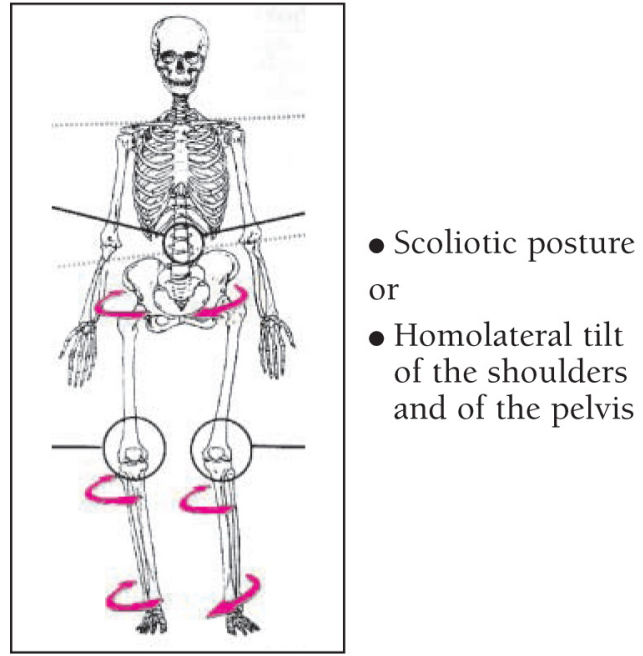

Figure 10

Consequences of a defect in convergence.

the ocular muscles by having the patient gaze steadily at a mirror handle moving laterally and vertically at a distance of $20 \mathrm{~cm}$ and then brought in to the base of the nose. The convergence is considered pathological if one eye converges in fits and starts or more slowly than the other or if the two eyes stimulated in convergence part in divergence.

When the malocclusion of patients who have dental cross bites is corrected and they are given a few orthoptic exercises good ocular convergence is restored.

If the belts do not produce their tampon effect scoliosis or a tendency to scoliosis develops, but the vertebral column will remain upright if the belts exert their tampon effect.

\section{3 - 5 - The masticatory apparatus}

The masticatory apparatus because of its anatomical location and its physiological function takes a significant part in the body's postural system.

The anterior and posterior muscular changes are biomechanically correlated with the muscles of mastication, the super and sub hyoid muscles, the sterno-cleido mastoid, the trapezius, and the pectorals.

When disequilibrium affects the tempero- mandibular joint, the tonic postural system decompensates, and when the tonic postural system falls out of equilibrium the TMJ is affected. Thus, patients with a natural Class I occlusion have a posture that is in equilibrium with the scapular planes and the hips well aligned, the lumbar and cervical curvatures in harmony, and with the face and the scapular and pelvic belts horizontal.

But examiners evaluating patients who have Class II malocclusions, overbites, or a loss of vertical dimension will note an advancement of the scapular plane.

Conversely, when the mandible is advanced, the scapula is in a posterior position.

\section{3 - 6 - Other factors playing a role in posture}

Any disturbance of oro-facial function has an effect on posture:

- breathing problems;

- tongue position at rest or during deglutition;

- problems of mastication (favoring one side over the other).

Information emanating from the periodontal membrane, during orthodontic treatment, occlusal over-load- 


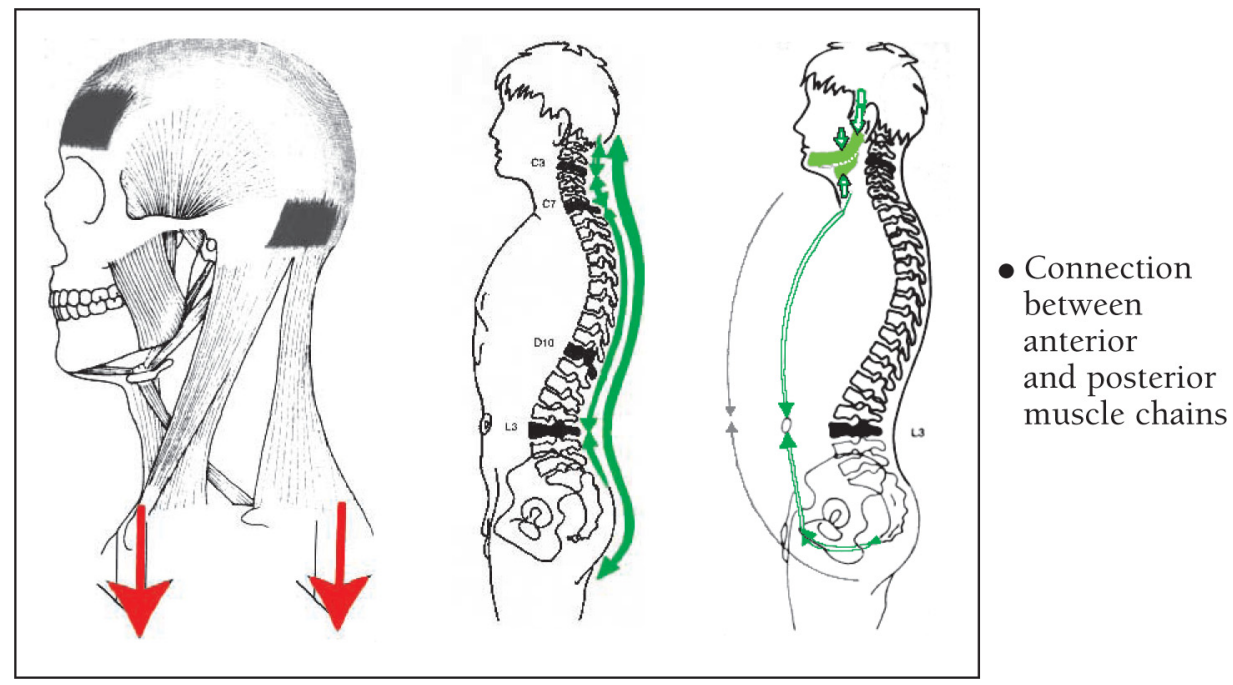

Figure 11

The masticatory apparatus after Busquet ${ }^{4}$.

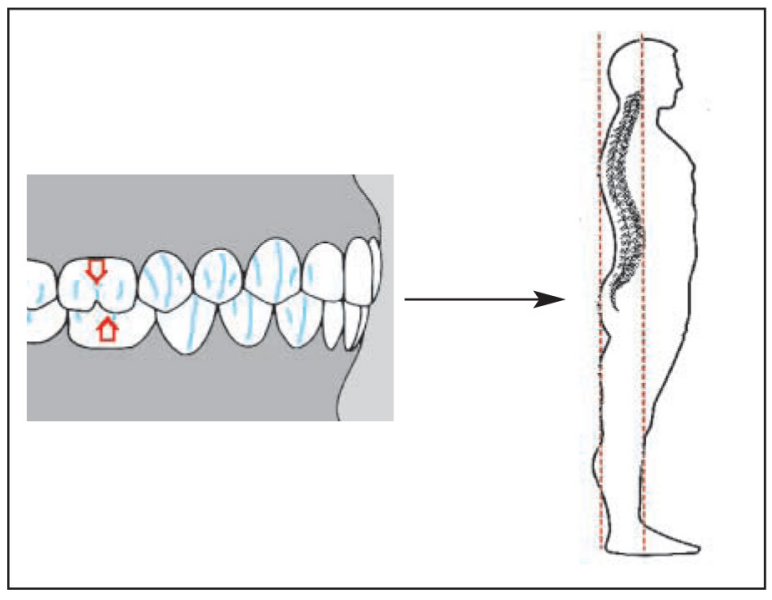

Figure 12

Reciprocal influences, Class I after Bricot ${ }^{3}$.

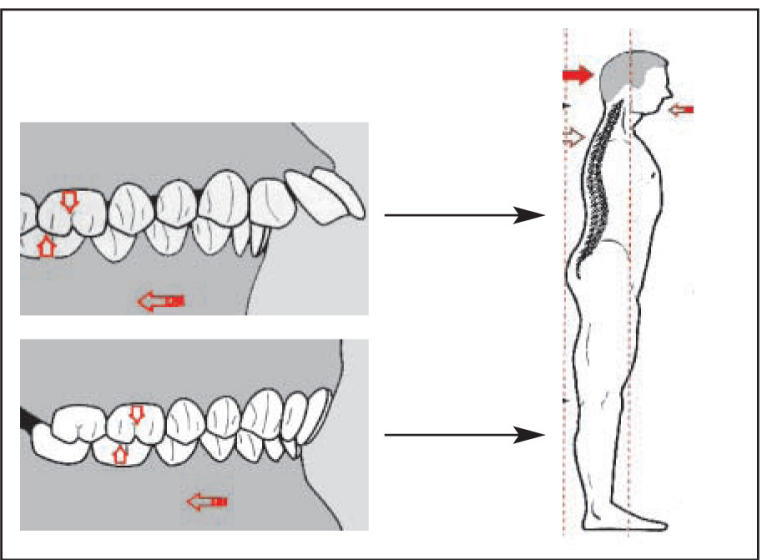

Figure 13

Reciprocal influences, Class // after Bricot ${ }^{3}$. 


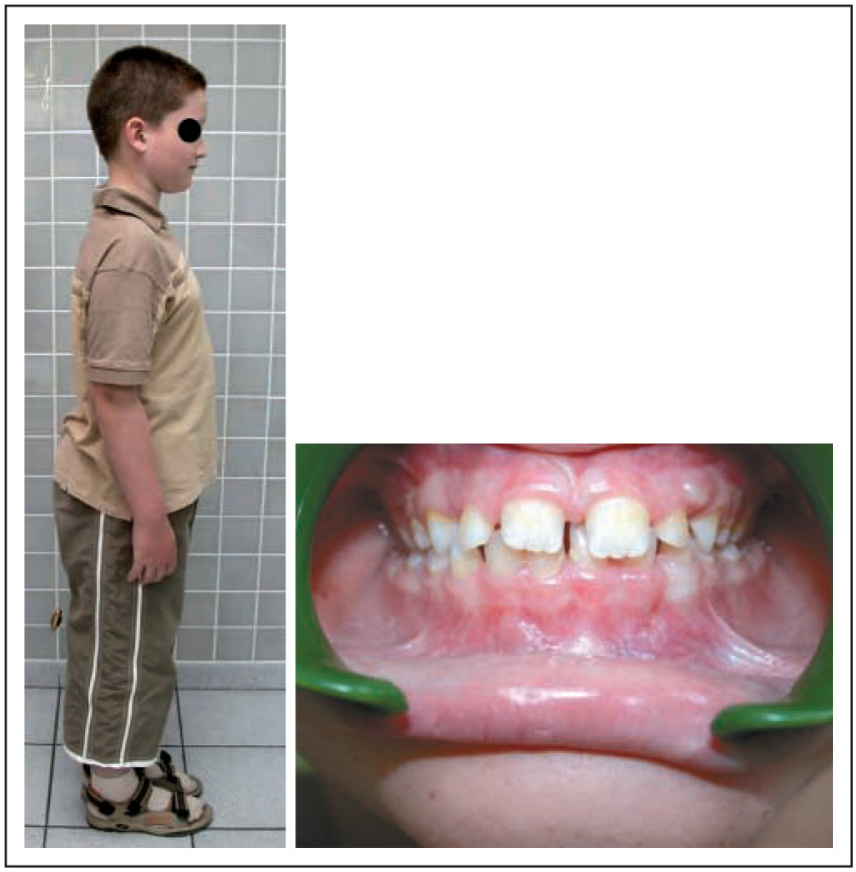

Figure 14

Anterior scapula in a patient with a deep bite.

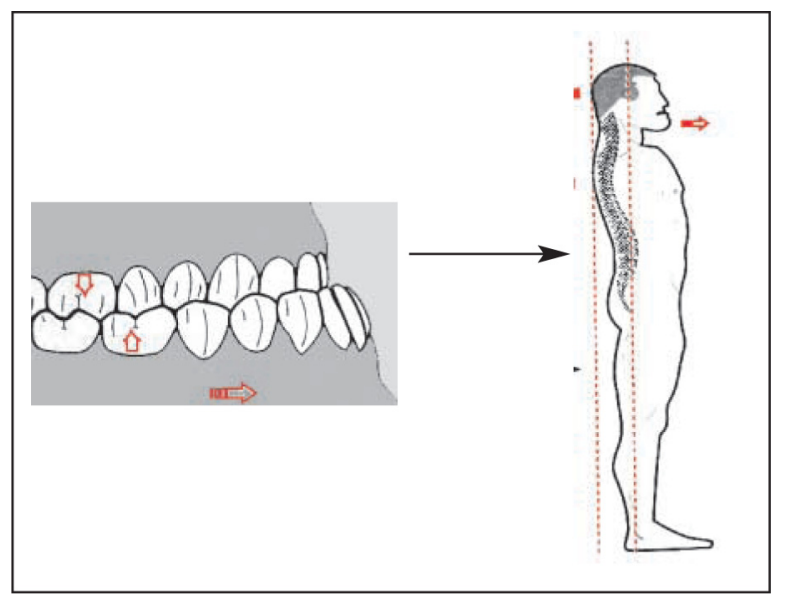

Figure 15

Reciprocal influences, Class III after Bricot ${ }^{3}$.

ing, sites of infection, from the muscles of mastication, in bruxism, perhaps, or from the TMJ all have repercussions in the postural system, usually mediated through interference with the trigeminal nerve. This type of disturbance can affect these nerves:
- the III oculomotor nerve innervating the pupils and the eyelids;

- the IV pathetic that serves the superior oblique muscle of the eye;

- the VI ocular motor nerve innervating the right external muscle of 


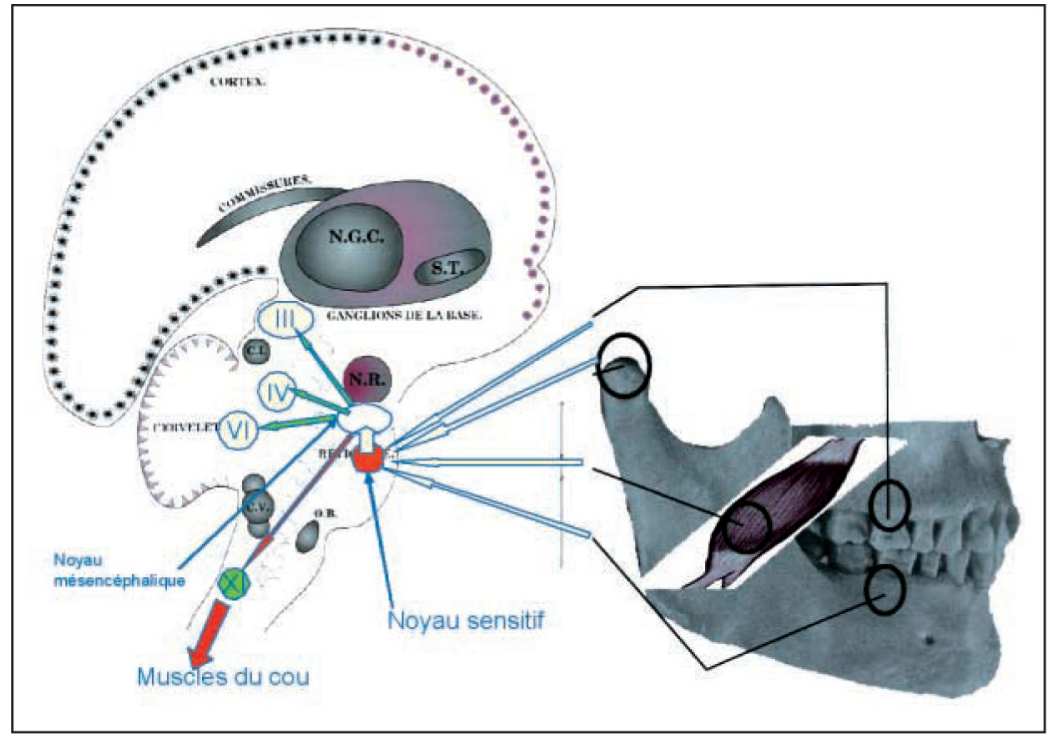

Figure 16

Interference with the trigeminal nerve after $\mathrm{Meyer}^{7}$ and Baron.

the eye that, when failing to relax, causes faults of ocular convergence;

- the XI spinal nerve serving the neck muscles.

We can add that posturologists pay serious attention to the galvanic action set off by amalgam and other metals used for restorations in the mouth not to mention the jewelry worn as piercings and cutaneous cervical scarring.

\section{4 - WHAT SHOULD BE DONE IN ORTHODONTIC OFFICES:}

\section{A SUCCINT POSTURAL ASSESSMENT SHOULD BE INTEGRATED IN THE ORTHODONTIC RECORDS}

In order to prepare a postural evaluation of patients correctly, ideally we should ask them to strip to their undergarments. Since some orthodontists and many patients may be reluctant to do that, the best alternative is to ask them to wear the lightest possible sports outfit for this procedure. With a $10 \mathrm{~cm}$ square rule the examiner can visualize the extent of shoulder and pelvic tilting in a frontal view as well as postural troubles in the sagittal plane and point these out to parents.

Examiners can also use a plumb line placed along the hips to evaluate postural difficulties in the sagittal plane as well as cervical and lumbar curvatures.

A postural examination of Marie reveals that her right shoulder is lower 


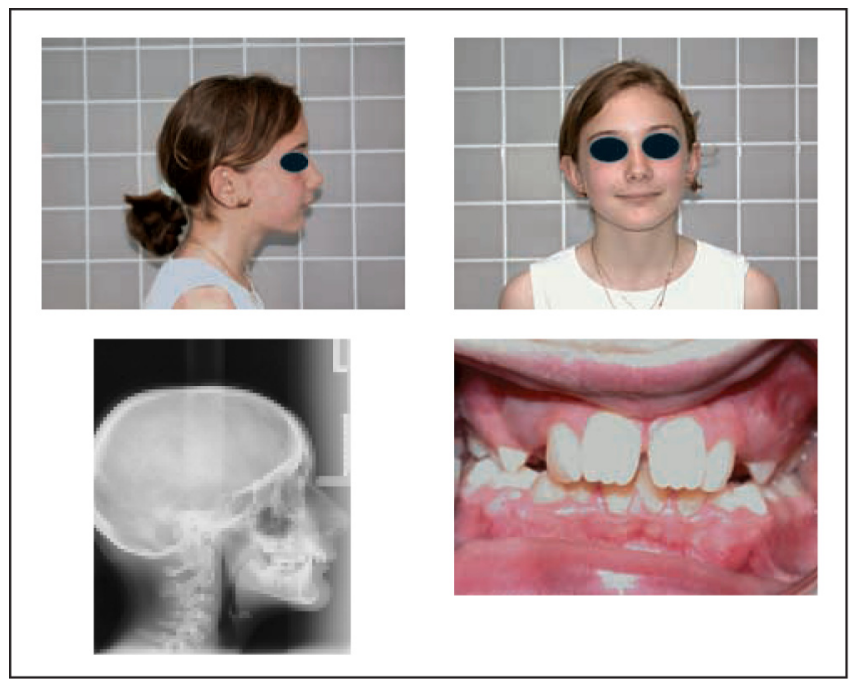

Figure 17

Marie.

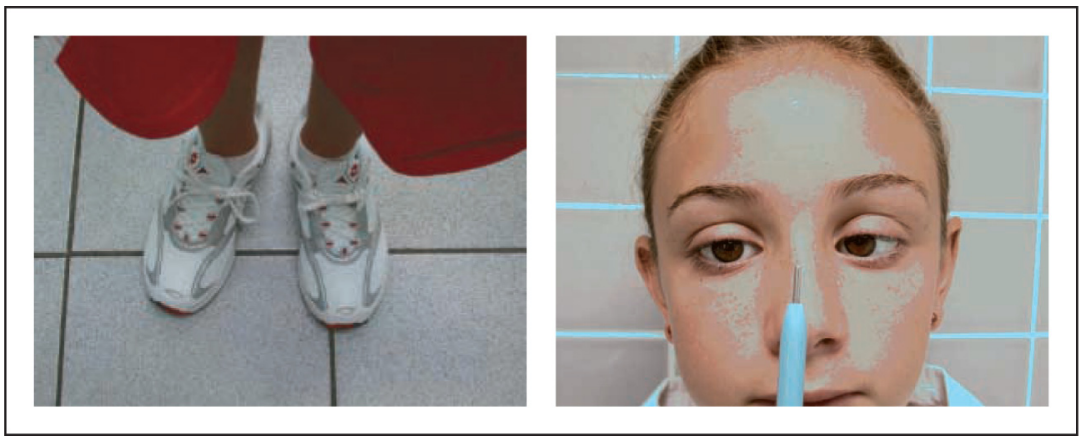

Figure 18

Showing divergent feet and hypo-convergence of the right eye.

than her left. This can also be seen by an examiner bent over in front of the patient where the difference in the height of the wrists can be noted, at the level of the radial styloids. But examiners should take into account the fact that right handed people usually have right shoulders lower than their left.

Examiners can study the tilt of the pelvis by placing their hands on the iliac crest. For this patient, the right hand will be lower. In this type of case patients do not hold their heads erect but tilt it to the right. If the examiner gently guides the head to an upright position such patients feel ill at ease and tilt their heads back to the original position.

By placing cotton roll between the teeth the examiner can neutralize the signals sent out by the occlusion and patients will upright their heads spontaneously thanks to this elimination of this faulty postural data. 


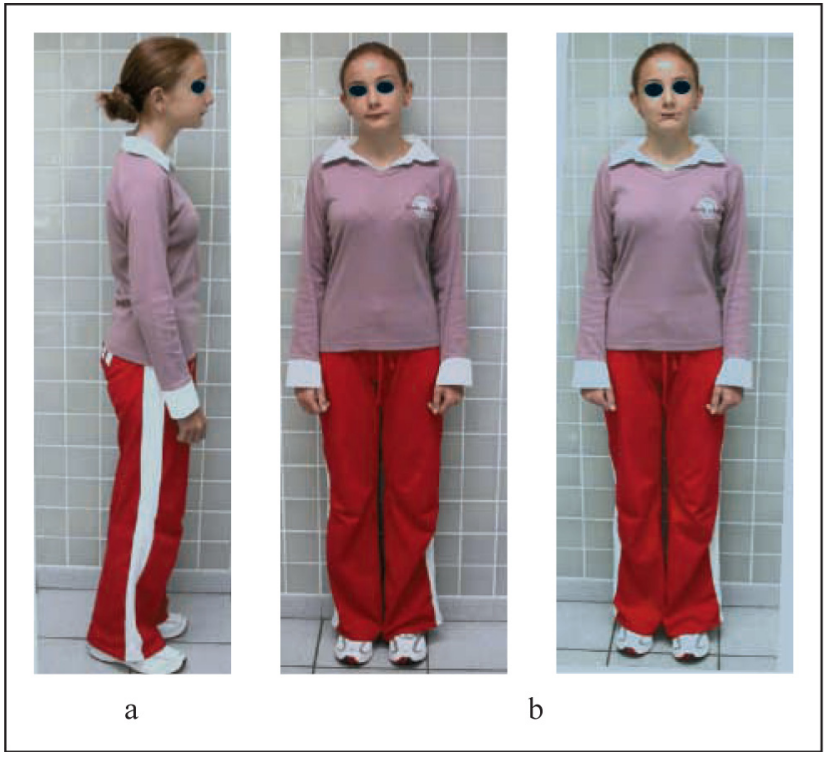

Schema: a) profile view: scapula and head in advance; b) full face: head leaning to the right; c) full face: head becomes upright when cotton roll is placed between the teeth.

This succinct assessment allows the examiner to detect a postural problem that ought to be corrected before orthodontic therapy begins.

\section{- Case $n^{\circ} 2$ - Jules}

This boy's left shoulder is lower than his right, his right leg is bent, and the examination of his back proved to be most interesting.

His left foot is valgus, turned outward. An orthopedist would study him barefooted. Unfortunately we usually see our patients when they are wearing sneakers packed with "shock absorber" material that is quite harmful to the wearer's posture.

His head and scapula are in an anterior position.
Marie standing

Figure 19

a: profile view, note anterior scapula;

b: full face, right shoulder and ilium are lower.

\section{Referring a patient to a physician competent in posturology}

When orthodontists prepare to treat patients with this type of problem, they should first refer them to competent physicians who will take a careful history and carry out a full postural analysis with assessment of possible future pain sites. The examination will include the sagittal, the frontal, and the horizontal planes. The weight bearing capability of the feet will be assessed as to its distribution between the feet and in forward and backward walking. The physician will also evaluate the ocular receptors, will look for pathological scars, any blockage at any level of the spinal column, and for visceral mobility and motility problems.

\section{Postural treatment should be under- taken by a multi-disciplinary team}

The goal of an orthodontist's taking postural evaluation is find out 


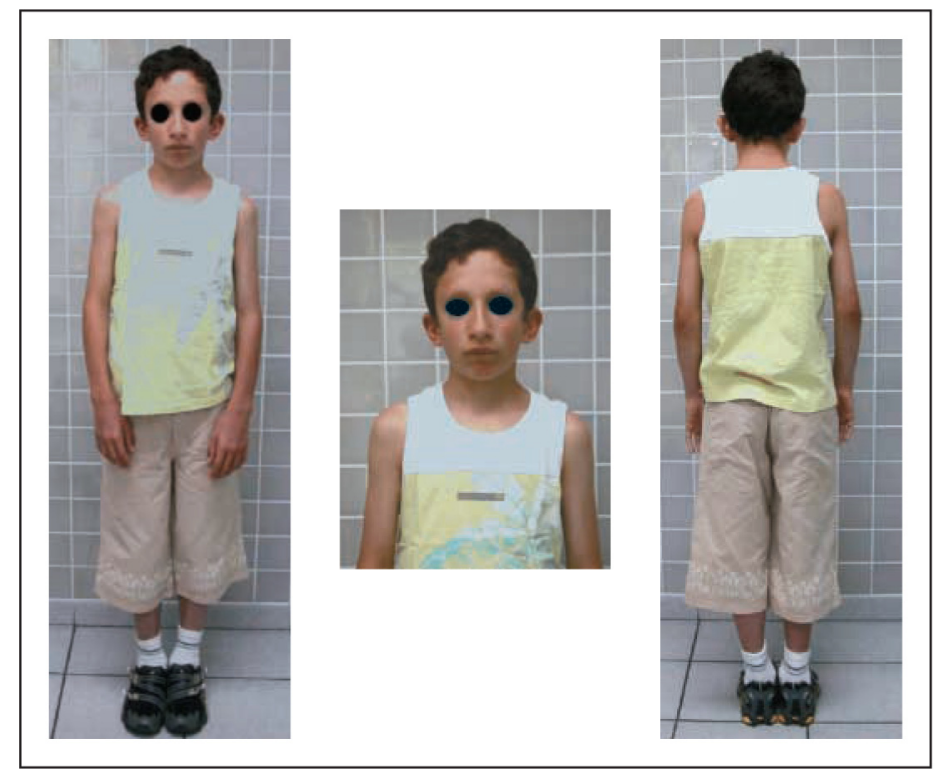

Figure 20

Jules.

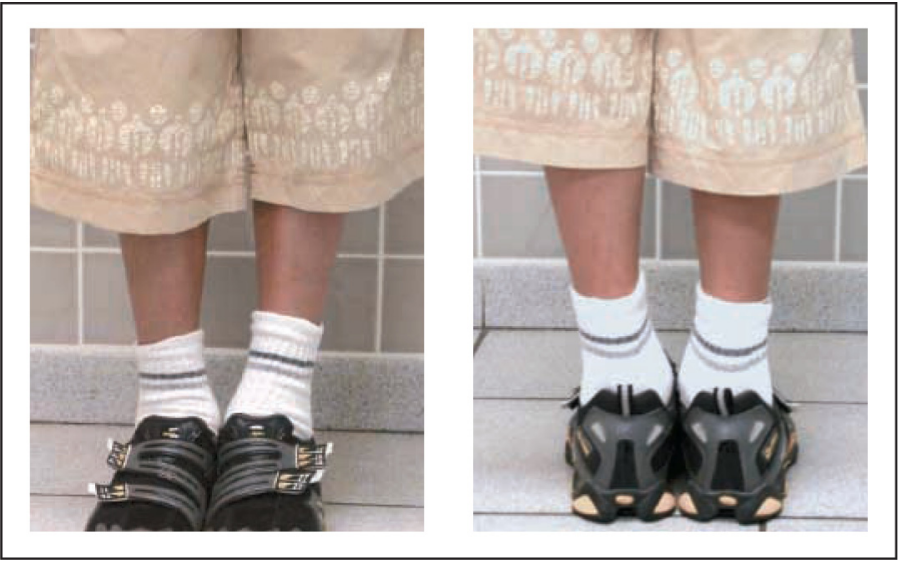

Figure 21

His feet.

if any receptors are mal-functioning and to refer patients when indicated to the proper specialist that might be a podiatrist, an orthopedist, a physical therapist, an osteopath, or another dentist. Physicians treating patients for postural problems usually see them every four months the first year, then twice a year for growing children. There are a variety of schools of thought in posturology but they all agree on the importance of correcting mal-functioning receptors. 


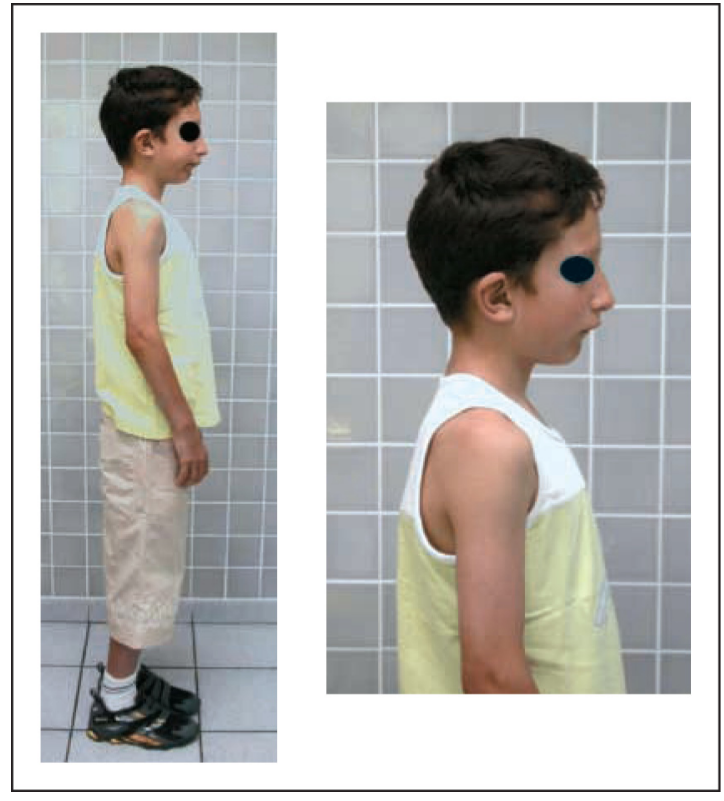

It is advisable to correct postural problems 4 to 6 months before orthodontic treatment begins and then have it continue as orthodontic therapy proceeds.

\section{- Case n 3 - Maxime}

This 11 year old boy with a retruded mandible had postural problems that included pelvis and shoulders tilted in
Figure 22

Head and scapula in anterior positions. opposite directions. He was treated with corrective shoes equipped with Bricot soles 4 months before he began wearing a functional orthodontic appliance and starting oro-facial myo-functional therapy.

Pre-orthodontic postural therapy makes it possible for myo-functional treatment to work effectively and to have stable results.

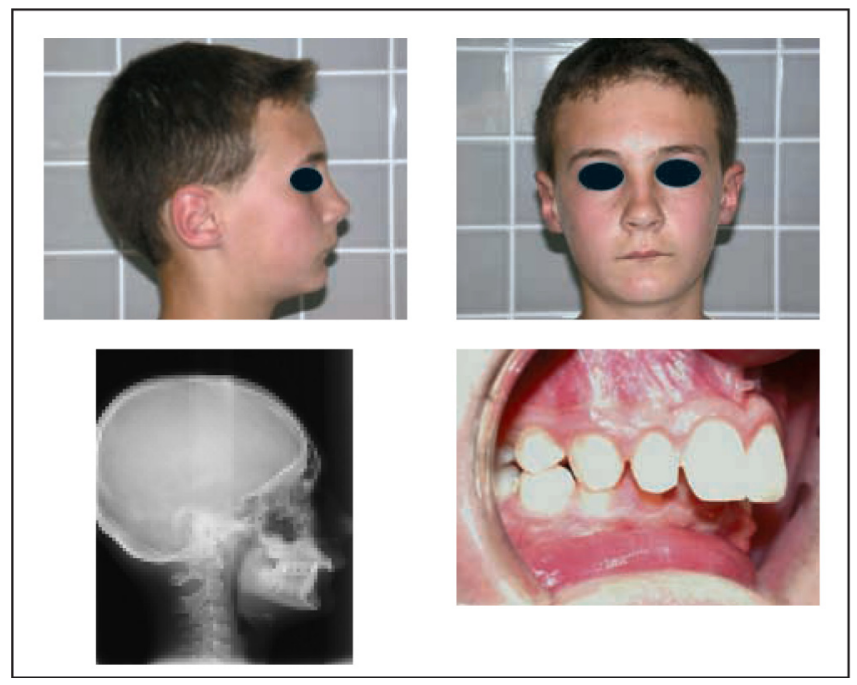

Figure 23

Maxime. 


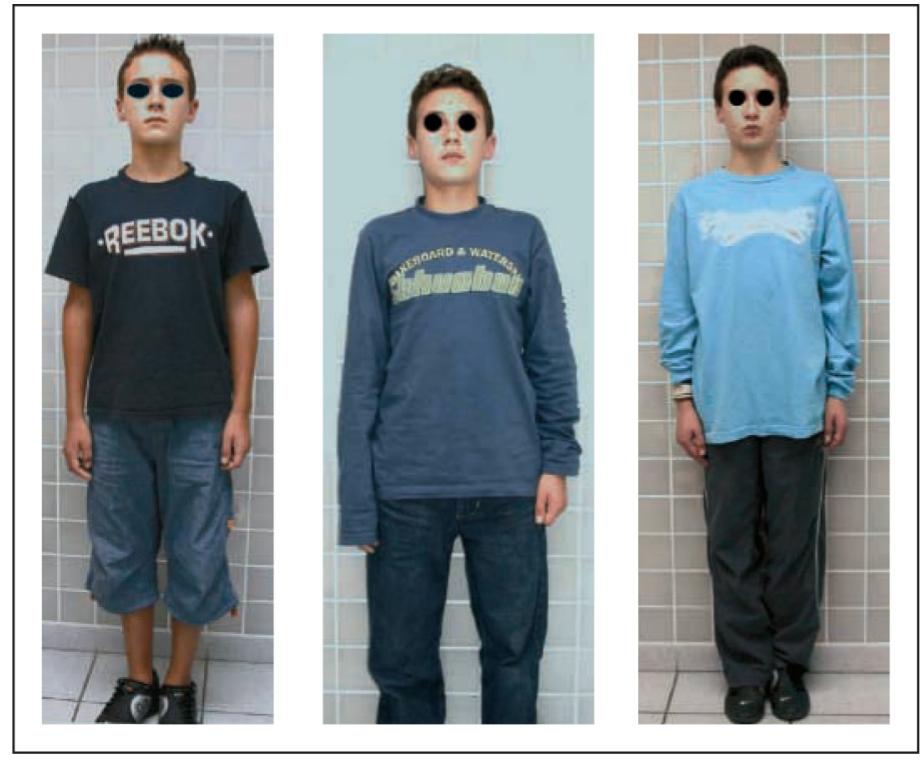

Figure 24

Maxime frontal view.

(1)

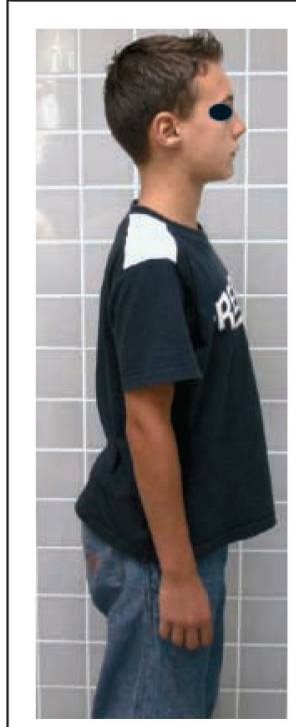

(2)

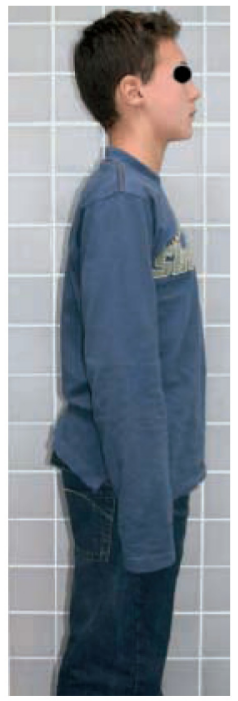

(3)

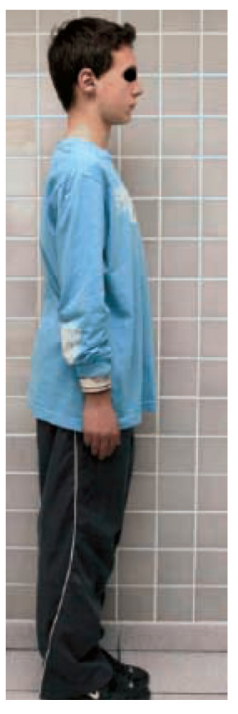

Figure 25

Maxime profile view.
Here one can see the straightening of the scapular plane and the decrease of cervical curvature.

(1) before postural treatment;
(2) 4 months after the beginning of postural therapy;

(3) after completion of postural treatment and 6 months of functional therapy. 


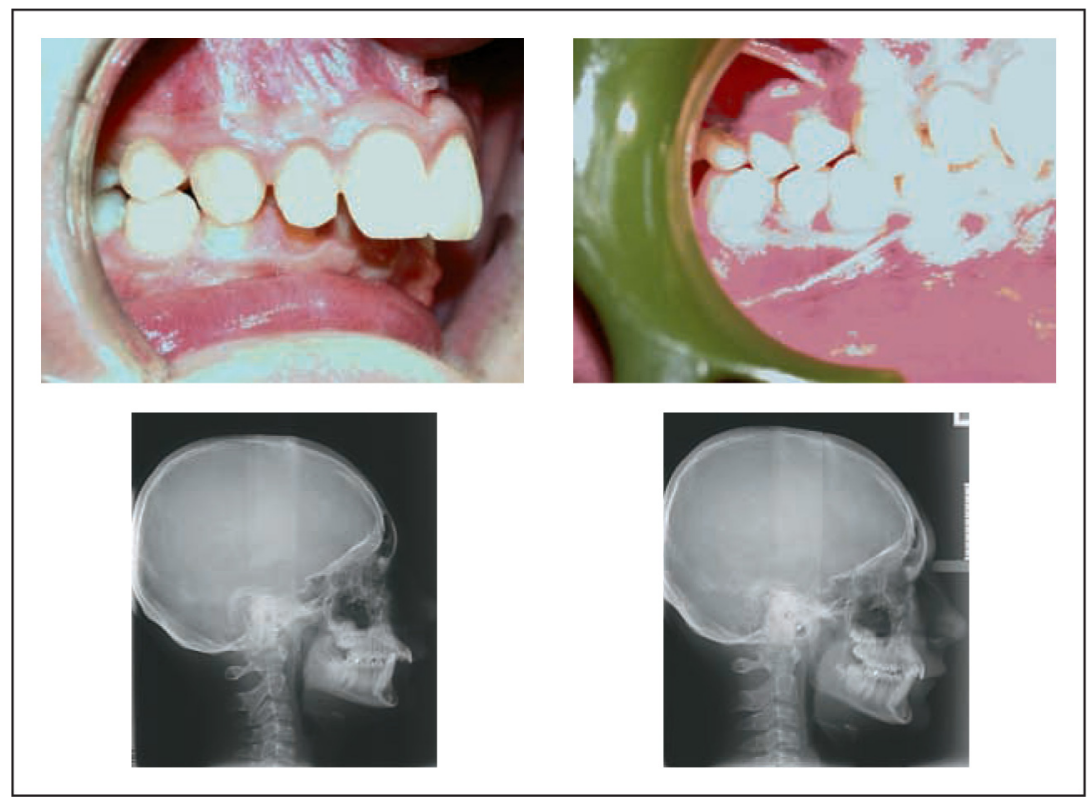

Figure 26

Re-establishment of Class I occlusion.

A Class 1 occlusion has been quickly reestablished and will be followed by a period of full-banded finishing procedures after which there will be little risk of relapse.

\section{5 - THE SCOLIATIC PATIENT}

Scoliosis is a curvature, and possible rotation, of the spine that may be congenital or the result of diseases such as cerebral palsy or rickets. It is characterized by progressive displacement of vertebra with respect to each other in all three dimensions of space with:

- lateral inflexion which reflects displacement in the frontal plane;

- extension or flatness of the back reflecting a displacement in the sagittal plane;

- a rotation reflecting a vertebral movement in the horizontal plane: appearing clinically as an abnormal curvature or bulge;
- scoliosis occurs most frequently idiopathically during adolescence, $80 \%$ of the cases in girls occurring between the ages of 11 and 13 and $20 \%$ of the time in boys between the ages of 13 and 15;

- usually scoliosis develops chaotically and without warning.

\section{- A clinical case}

This 12 year old girl had a malocclusion with no transverse discrepancy except an impacted upper right cuspid. Treatment proceeded uneventfully until a few months before the scheduled day of band removal when a serious mandibular deviation became apparent. 
When a postural assessment was made a slight scoliosis was found. In consultation with the physician treating the girl we decided to remove the appliances immediately so as not to interfere with the scoliosis therapy. As this physical therapy continued over the next few months the mandible progressively moved back to its correct position. It will be necessary to wait for the end of the growth period to finish the orthodontic treatment while, of course, the spinal column will also be closely monitored.

How should patients with scoliosis be treated orthodontically?

There is a wide difference of opinion on this point; many physical therapists have pointed out that scoliosis often appears after conclusion of orthodontic treatment; others respond that the condition was probably preexistent.

The cause and effect relationship is highly uncertain, but, at the very least, orthodontists should be aware that orthodontic treatment may have some kind of impact on the spinal column. According to some posturologists the placement of an orthodontic appliance has a great effect on the postural system.

If scoliosis is diagnosed before the beginning of therapy, orthodontists should undertake treatment with the utmost prudence! Dr. Bricot goes so far as to say that any full-banded orthodontic treatment should be postponed until the end of the growth period so as not to risk any adverse stimulation of the tonic postural system. But Dr. Mauroy ${ }^{6}$ advises that girls between the ages of 11 and 13 can began orthodontic therapy as long as the spinal column is kept under strict surveillance and, if needed, treated for scoliosis simultaneously. So, in these situations of postural risk, we should adapt our treatments or suspend them entirely.

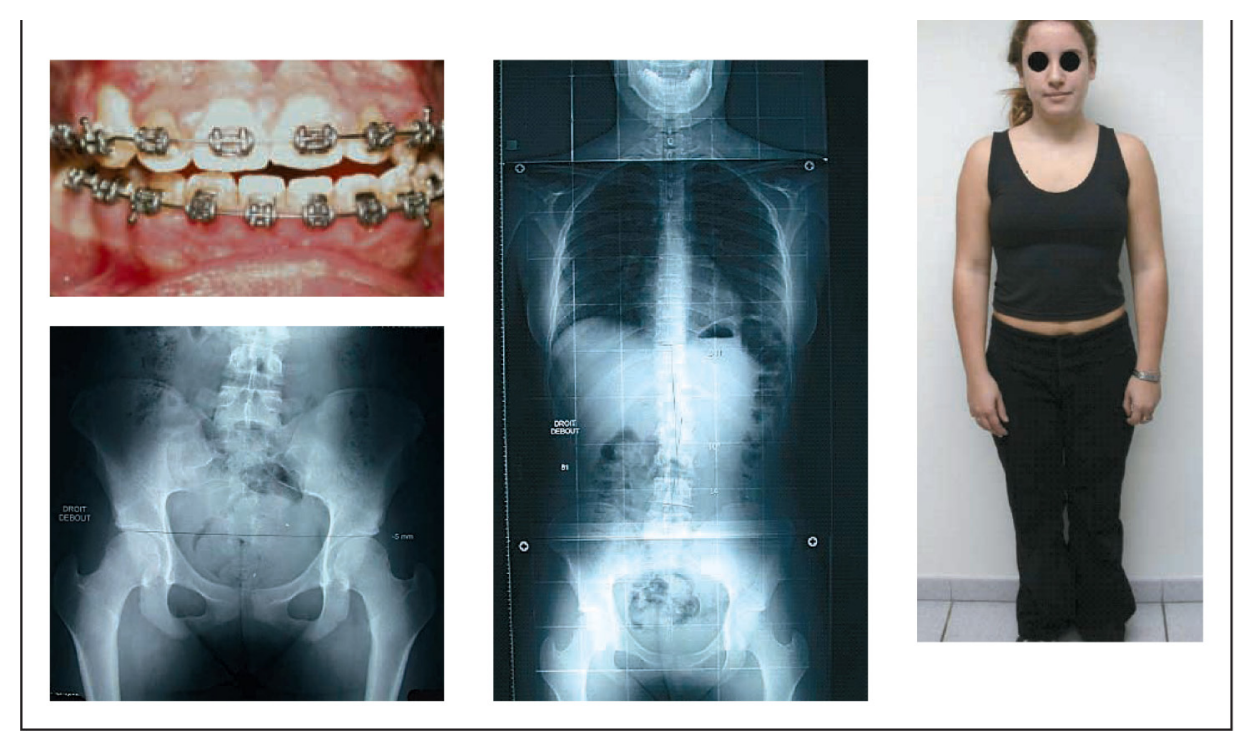

Figure 27

Scoliosis. 

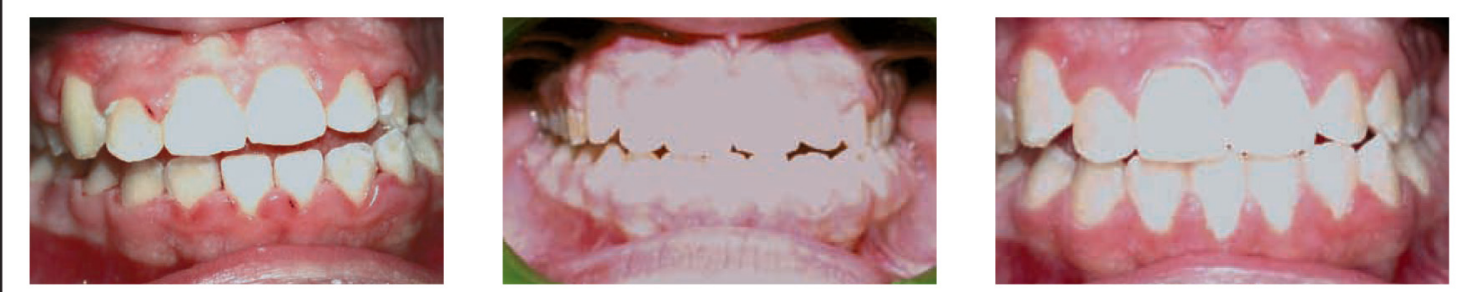

Figure 28

Removal of orthodontic appliances for scoliosis therapy.

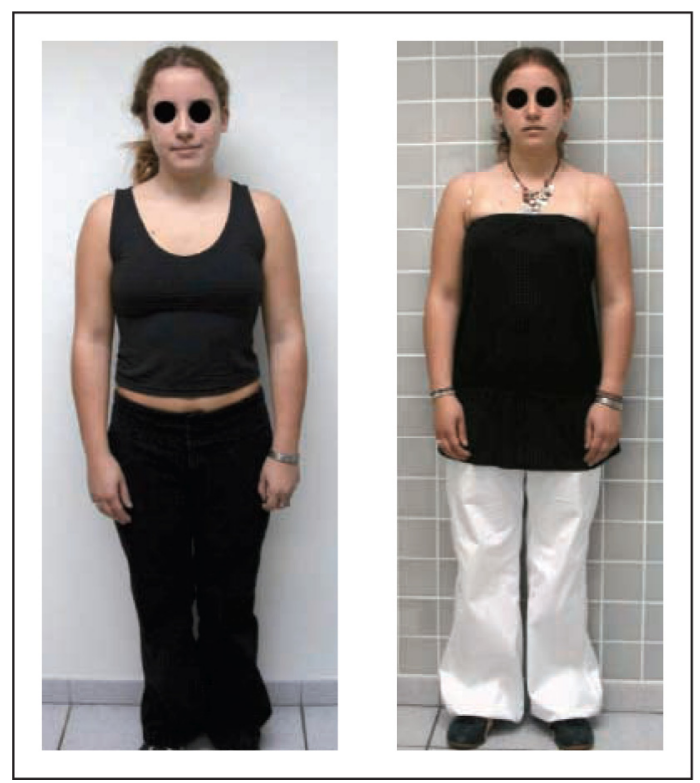

Figure 29

Pelvis straightened mandible re-centred.

\section{6 - CONCLUSION}

Orthodontists should make postural assessments of their patients before treatment in order to detect any possible disequilibrium in the postural system. If such a discrepancy is found, multidisciplinary therapy may be indicated. In all cases, orthodontists should be aware of the totality of their patients' over-all postural status. If a postural discrepancy appears during the course of mechano-therapy they should adapt it and, where necessary, discontinue it. Orthodontic treatment can be a cause of serious disturbances through deleterious interference with the trigeminal nerve. Not only our patients but also their bodies should accept the treatment that we propose. 


\section{REFERENCES}

1. Ait-Abbas. Occlusion et posture de l'enfant. Mémoire pour DU d'occlusodontologie. Toulouse, 1992.

2. Bricot B. La reprogrammation posturale globale. Sauramps Médical, 1996.

3. Bricot B. Effets de l'occlusion sur le système postural. Étude de septembre 1999, Marseille.

4. Busquet L. Les chaïnes musculaires et traitement du crane. Éditions Busquet, 2006.

5. Clauzade MA, Daraillans B. Concept ostéopathique de l'occlusion. 1989.

6. De Mauroy. La scoliose. Sauramps Médical, 1996.

7. Meyer J. Participation des afférences trigéminales dans la régulation tonique posturale orthostatique. Intérêt de l'examen systématique du système manducateur chez les sportifs de haut niveau. Thèse DSO, 1977. 